Article

\title{
Self-Assembly of Low-Molecular-Weight Asymmetric Linear Triblock Terpolymers: How Low Can We Go?
}

\author{
Christina Miskaki ${ }^{1}$ (), Ioannis Moutsios ${ }^{1}$, Gkreti-Maria Manesi ${ }^{1}$, Konstantinos Artopoiadis ${ }^{1}$, \\ Cheng-Yen Chang ${ }^{2}$, Egor A. Bersenev ${ }^{3,4}{ }^{-0}$, Dimitrios Moschovas ${ }^{1,3}$, Dimitri A. Ivanov ${ }^{3,4,5}{ }^{(0}$, \\ Rong-Ming $\mathrm{Ho}^{2}$ and Apostolos Avgeropoulos $1,3, *$ it
}

1 Department of Materials Science Engineering, University of Ioannina, University Campus-Dourouti, 45110 Ioannina, Greece; xris.misk@gmail.com (C.M.); imoutsios@uoi.gr (I.M.); gretimanesi@uoi.gr (G.-M.M.); kartopoiades@gmail.com (K.A.); dmoschov@uoi.gr (D.M.)

2 Department of Chemical Engineering, National TsingHua University, Hsinchu 30013, Taiwan; joe950427@gmail.com (C.-Y.C.); rmho@mx.nthu.edu.tw (R.-M.H.)

3 Faculty of Chemistry, Lomonosov Moscow State University (MSU), GSP-1, 1-3 Leninskiye Gory, 119991 Moscow, Russia; bersenev.ea@phystech.edu (E.A.B.); dimitri.ivanov@uha.fr (D.A.I.)

4 Institute of Problems of Chemical Physics, Russian Academy of Sciences, Chernogolovka, 142432 Moscow, Russia

5 Institut de Sciences des Matériaux de Mulhouse-IS2M, CNRS UMR7361, 15 Jean Starcky, 68057 Mulhouse, France

* Correspondence: aavger@uoi.gr; Tel.: +30-26-5100-9001

Academic Editor: Derek J. McPhee

Received: 5 November 2020; Accepted: 23 November 2020; Published: 25 November 2020

\begin{abstract}
The synthesis of two (2) novel triblock terpolymers of the ABC type and one (1) of the BAC type, where $A, B$ and $C$ are chemically different segments, such as polystyrene (PS), poly(butadiene) $\left(\mathrm{PB}_{1,4}\right)$ and poly (dimethylsiloxane) (PDMS), is reported; moreover, their corresponding molecular and bulk characterizations were performed. Very low dimensions are evident from the characterization in bulk from transmission electron microscopy studies, verified by small-angle $\mathrm{X}$-ray data, since sub-16 $\mathrm{nm}$ domains are evident in all three cases. The self-assembly results justify the assumptions that the high Flory-Huggins parameter, $\chi$, even in low molecular weights, leads to significantly well-ordered structures, despite the complexity of the systems studied. Furthermore, it is the first time that a structure/properties relationship was studied for such systems in bulk, potentially leading to prominent applications in nanotechnology and nanopatterning, for as low as sub-10 $\mathrm{nm}$ thin-film manipulations.
\end{abstract}

Keywords: linear triblock terpolymers; anionic polymerization; sequential addition of monomers; SEC; ${ }^{1} \mathrm{H}-\mathrm{NMR}$; TEM; SAXS; self-assembly in bulk; Flory-Huggins interaction parameters $(\chi)$

\section{Introduction}

It is well-known that microphase separation in block copolymers strongly depends on $\chi N$ and $\varphi$ values, where $N$ is the degree of polymerization, $\chi$ is the Flory-Huggins interaction parameter and $\varphi$ is the volume fraction of each block. Over the last decades, several two-phase morphologies have been obtained from numerous types of diblock copolymers, rendering their use in nanotechnology applications, due to the exquisite properties they exhibit, by altering their molecular characteristics (especially molecular weight and volume fraction) [1-4]. These copolymers can be applied as nanolithography masks [5-9], thin films [10-14], nanostructured membranes [15-17], etc. The use of various diblock copolymers in such applications has been extensively studied, but the ever-growing demand on novel morphologies, unattainable by diblock copolymers, has shifted the interest to corresponding linear triblock terpolymers [18]. 
Linear triblock terpolymers have been reported to exhibit well-defined three-phase morphologies, due to the third chemically different block. It is documented that the morphologies are significantly affected by the block sequence ( $\mathrm{ABC}$ vs. $\mathrm{BCA}$ vs. $\mathrm{CAB}$ ), the volume fraction ratio and the values of the Flory-Huggins interaction parameters $\left(\chi_{\mathrm{AB}}, \chi_{\mathrm{AC}}\right.$ and $\left.\chi_{\mathrm{BC}}\right)$ [19-22].

Table 1 summarizes the data on already reported linear triblock terpolymers in the literature [23-74], and, more specifically, block sequence, number (or weight) average molecular weight range and the annealing conditions used, together with the corresponding reference. It is straightforward that all cases already studied involve various types of block sequences with relatively high number average molecular weights, and their microphase separation is studied mostly after thermal annealing and appropriate staining conditions with only a few discrepancies evident.

Table 1. Linear triblock terpolymer block sequences studied in the literature [23-74]. The total number average molecular weight range is given, together with the annealing conditions (if any) and the observed morphologies, in all cases.

\begin{tabular}{|c|c|c|c|c|c|}
\hline No. & Block Sequence & $\begin{array}{l}\text { Molecular Weight Range } \\
\text { (kg/mol) }\end{array}$ & Annealing & Observed Morphology & References \\
\hline 1 & PS- $b$-PB ${ }_{1,4}-b$-P4VP & $74-113$ & $60^{\circ} \mathrm{C}, 14 \mathrm{~h}$ & Ball in Box, LAM & {$[23,24]$} \\
\hline 2 & PS- $b$-PA- $b$-PI & $131-198$ & $\mathrm{n} / \mathrm{a}$ & $\mathrm{LAM}, \mathrm{C}_{\mathrm{h}} \mathrm{C}$ & {$[25]$} \\
\hline 3 & PS- $b$-PB- $b$-P4VP & $65-210$ & $\mathrm{n} / \mathrm{a}$ & Ball in Box, LAM & [26] \\
\hline 4 & PI- $b$-PS- $b$-P2VP & $36-279$ & $120^{\circ} \mathrm{C}, 10$ days & LAM, OTDD, CYL, SPH & {$[20-22,27]$} \\
\hline 5 & PS- $b$-PI- $b$-P2VP & 43 & $120^{\circ} \mathrm{C}, 7$ days & LAM, $\mathrm{C}_{\mathrm{h}} \mathrm{C}$ & [19] \\
\hline 6 & PS- $b$-P2VP- $b$-PB & $111-258$ & $\mathrm{n} / \mathrm{a}$ & $\mathrm{n} / \mathrm{a}$ & [28] \\
\hline 7 & PS- $b$-PI- $b$-P2VP & 196-201 & $120^{\circ} \mathrm{C}, 7$ days & OTDD, LAM & [29] \\
\hline 8 & $\begin{array}{c}\text { PS- } b \text {-PB } B_{1,2}-b \text {-PMMA } \\
\text { and } \\
\text { PS- } b \text {-PEB- } b \text {-PMMA }\end{array}$ & $\begin{array}{l}225-245 \\
\text { and } \\
226-248\end{array}$ & $\begin{array}{c}85^{\circ} \mathrm{C}, 2 \text { days } \\
150^{\circ} \mathrm{C}, 2 \mathrm{~h} / 4 \mathrm{~h} / 6 \mathrm{~h} \\
\text { and } \\
160^{\circ} \mathrm{C}, 5 \text { days }\end{array}$ & LAM, CR, LC, LS & {$[30,31]$} \\
\hline 9 & PS- $b$-PB ${ }_{1,2}-b$-PMMA & $206-218$ & $\begin{array}{c}100^{\circ} \mathrm{C}, 2 \text { days } \\
170^{\circ} \mathrm{C}, 2 \mathrm{~h} / 4 \mathrm{~h} / 6\end{array}$ & $\mathrm{C}_{\mathrm{h}} \mathrm{C}, \mathrm{C}_{\mathrm{a}} \mathrm{C}, \mathrm{HEL}$ & [32] \\
\hline 10 & $\begin{array}{c}\text { PS- } b-\mathrm{PB}_{1,2}-b \text {-PCL } \\
\text { PS- } b-\mathrm{PB}_{1,2}-b \text {-PMMA }\end{array}$ & $105-137$ & $\mathrm{n} / \mathrm{a}$ & $\mathrm{n} / \mathrm{a}$ & [33] \\
\hline 11 & $\begin{array}{c}\text { and } \\
\text { PS- } b \text {-PEB- } b \text {-PMMA }\end{array}$ & $117-245$ & $160^{\circ} \mathrm{C}, 4 \mathrm{~h}$ & KP, LAM, LC & [34] \\
\hline 12 & $\mathrm{~PB}_{1,2}-b$-PS- $b$-PMMA & 192 & $\begin{array}{c}100^{\circ} \mathrm{C}, 2 \text { days } \\
170^{\circ} \mathrm{C}, 6 \mathrm{~h}\end{array}$ & $\mathrm{CYL}_{\mathrm{T}}$ & [35] \\
\hline 13 & $\begin{array}{c}\text { PS- } b \text {-PB } B_{1,2}-b \text {-PMMA } \\
\text { and } \\
\text { PS- } b \text {-PEB- } b \text {-PMMA }\end{array}$ & $\begin{array}{l}78-140 \\
\text { and } \\
80-124\end{array}$ & $\begin{array}{c}185^{\circ} \mathrm{C}, 6 \mathrm{~h} \\
\text { and } \\
185^{\circ} \mathrm{C}, 2 \mathrm{~h} / 4 \mathrm{~h} / 6 \mathrm{~h}\end{array}$ & $\begin{array}{c}\mathrm{C}_{\mathrm{h}} \mathrm{C}, \mathrm{HEL}, \mathrm{C}_{\mathrm{a}} \mathrm{C}, \mathrm{uC}_{\mathrm{i}} \mathrm{C} \\
\mathrm{S}_{\mathrm{o}} \mathrm{C}\end{array}$ & [36] \\
\hline 14 & PS- $b$-PVP- $b$-PtBMA & 293 & $\mathrm{n} / \mathrm{a}$ & LAM & [37] \\
\hline 15 & $\begin{array}{c}\text { PS- } b \text {-PB } \text { P }_{1,2}-b \text {-PMMA } \\
\text { and } \\
\text { PS- } b \text {-PEB- } b \text {-PMMA }\end{array}$ & $\begin{array}{l}88-241 \\
\text { and } \\
90-242\end{array}$ & $170^{\circ} \mathrm{C}, 10$ days & $\mathrm{S}_{\mathrm{o}} \mathrm{S}$ & [38] \\
\hline 16 & $\mathrm{PI}_{1,4}-b-\mathrm{PB}_{1,2}-b-\mathrm{PS}$ & $48-74$ & $\begin{array}{l}60^{\circ} \mathrm{C}, 2 \text { days } \\
120^{\circ} \mathrm{C}, 3 \mathrm{~h}\end{array}$ & two-phase morphology & [39] \\
\hline 17 & $\begin{array}{l}\text { PS- } b-\mathrm{PB}_{1,2}-b \text {-PMMA } \\
\text { PS- } b-\mathrm{PB}_{1,2}-b \text {-PMMA }\end{array}$ & $\begin{array}{l}215 \\
121\end{array}$ & $120^{\circ} \mathrm{C}, 3-5$ days & LAM, HPC & [40] \\
\hline 18 & $\begin{array}{c}\text { and } \\
\text { PS- } b \text {-PEB- } b \text {-PMMA }\end{array}$ & $\begin{array}{l}\text { and } \\
122\end{array}$ & $185^{\circ} \mathrm{C}, 2-6 \mathrm{~h}$ & LAM, KP & [41] \\
\hline 19 & PH- $b$-P2T- $b$-PF & 61 & $\mathrm{n} / \mathrm{a}$ & LAM & [42] \\
\hline 20 & $\begin{array}{l}\mathrm{PI}_{1,4}-b \text {-PS- } b \text {-PDMS } \\
\text { PS- } b \text {-PB } 1,2-b \text {-P2VP }\end{array}$ & $\begin{array}{c}41 \\
62-137\end{array}$ & $\mathrm{n} / \mathrm{a}$ & CSG & [43] \\
\hline 21 & $\begin{array}{c}\text { and } \\
\mathrm{PB}_{1,2}-b \text {-PS- } b \text {-P2VP }\end{array}$ & $\begin{array}{l}\text { and } \\
84-210\end{array}$ & $150^{\circ} \mathrm{C}, 6 \mathrm{~h}$ & LAM, $\mathrm{C}_{\mathrm{h}} \mathrm{C}, \mathrm{CSG}$ & [44] \\
\hline 22 & PS- $b$-PI- $b$-PDMS & 59 & $\mathrm{n} / \mathrm{a}$ & $\mathrm{n} / \mathrm{a}$ & [45] \\
\hline 23 & PS- $b$-PB $1,2-b$-P2VP & 71 & $150^{\circ} \mathrm{C}, 6 \mathrm{~h}$ & CSG & [46] \\
\hline 24 & PS-b-PI- $b$-PEO & $19-30$ & $\begin{array}{l}80-225^{\circ} \mathrm{C} \\
0.5 \mathrm{~h}-120 \mathrm{~h}\end{array}$ & $\begin{array}{c}\text { LAM, } \mathrm{C}_{\mathrm{h}} \mathrm{C}, \mathrm{CSG}, \mathrm{PLS}, \\
\text { SPL }\end{array}$ & [47] \\
\hline 25 & PS- $b$-PEB- $b$-PMMA & $73-123$ & $170^{\circ} \mathrm{C}, 6 \mathrm{~h}$ & LAM, LC, KP & [48] \\
\hline 26 & PI- $b$-PS- $b$-PEO & $13-22$ & $\mathrm{n} / \mathrm{a}$ & LAM, Fddd $\left(\mathrm{O}^{70}\right)$ & [49] \\
\hline 27 & $\begin{array}{l}\text { PI- } b \text {-PS- } b \text {-PVME } \\
\text { PB }_{14}-b-\text { PS- } b-\mathrm{PI}_{34}\end{array}$ & $\begin{array}{c}32 \\
85-149\end{array}$ & $\mathrm{n} / \mathrm{a}$ & LAM & [50] \\
\hline 28 & $\begin{array}{c}\text { and } \\
\text { PS- } b-\mathrm{PB}_{1,4}-b-\mathrm{PI}_{3,4}\end{array}$ & $\begin{array}{l}\text { and } \\
133\end{array}$ & $130^{\circ} \mathrm{C}, 7$ days & LAM, HPC & [51] \\
\hline 29 & PS- $b$-P2VP- $b$-PtBMA & $76-140$ & $\mathrm{n} / \mathrm{a}$ & $\mathrm{C}_{\mathrm{h}} \mathrm{C}, \mathrm{CSG}, \mathrm{LAM}, \mathrm{PL}, \mathrm{UL}$ & [52] \\
\hline
\end{tabular}


Table 1. Cont.

\begin{tabular}{|c|c|c|c|c|c|}
\hline No. & Block Sequence & $\begin{array}{l}\text { Molecular Weight Range } \\
(\mathrm{kg} / \mathrm{mol})\end{array}$ & Annealing & Observed Morphology & References \\
\hline 30 & PI- $b$-PS- $b$-PEO & $13-25$ & $\mathrm{n} / \mathrm{a}$ & $\mathrm{Q}^{230}, \mathrm{LAM}, \mathrm{O}^{70}, \mathrm{Q}^{214}$ & [53] \\
\hline 31 & PI- $b$-PS- $b$-PEO & $19-43$ & $\mathrm{n} / \mathrm{a}$ & LAM, $\mathrm{O}^{70}$ & [54] \\
\hline 32 & PS- $b$-PFS ${ }^{\mathrm{a}}-b$-PMMA & 101-110 & $\begin{array}{l}120^{\circ} \mathrm{C}, 2 \mathrm{~h} \\
180^{\circ} \mathrm{C}, 36 \mathrm{~h}\end{array}$ & $\mathrm{HEL} / \mathrm{S}_{\mathrm{o}} \mathrm{C}, \mathrm{S}_{\mathrm{o}} \mathrm{S}$ & [55] \\
\hline 33 & PS- $b$-PB- $b$-PMMA & 170 & $\begin{array}{l}100^{\circ} \mathrm{C}, 1 \text { day } \\
170^{\circ} \mathrm{C}, 1 \text { day }\end{array}$ & dHEL & [56] \\
\hline $\begin{array}{l}34 \\
35\end{array}$ & $\begin{array}{l}\text { PI- } b \text {-PS- } b \text {-PFS } \\
\text { PS- } b \text {-PI- } b \text {-PMMA }\end{array}$ & $\begin{array}{c}82 \\
13.5-31\end{array}$ & $\begin{array}{c}150{ }^{\circ} \mathrm{C}, 4 \text { days } \\
\text { n/a }\end{array}$ & $\begin{array}{c}\mathrm{CYL}_{\mathrm{T}} \\
\mathrm{LAM}, \mathrm{Q}^{214}\end{array}$ & $\begin{array}{l}{[57]} \\
{[58]}\end{array}$ \\
\hline 36 & PB-b-P2VP- $b$-PtBMA & 61-165 & $\begin{array}{c}50{ }^{\circ} \mathrm{C}, 24 \mathrm{~h} \\
130^{\circ} \mathrm{C}\end{array}$ & $\begin{array}{c}\text { LAM/CSG, } \mathrm{C}_{\mathrm{h}} \mathrm{C}, \mathrm{LAM}, \\
\mathrm{S}_{\mathrm{O}} \mathrm{C}, \mathrm{HEL}_{\mathrm{O}} \mathrm{C}\end{array}$ & [59] \\
\hline 37 & PI- $b$-PS- $b$-P2VP & $26-150$ & $150^{\circ} \mathrm{C}, 7$ days & LAM, UL & [60] \\
\hline 38 & PI- $b$-PS- $b$-P4VP & 77 & $\mathrm{n} / \mathrm{a}$ & HPC & [61] \\
\hline 39 & PB- $b$-P2VP- $b$-PtBMA & 110 & $\mathrm{n} / \mathrm{a}$ & TPL & [62] \\
\hline 40 & $\begin{array}{c}\text { PS- } b-\mathrm{PB}_{1,2}-b-\mathrm{PCHD}_{1,4} \\
\text { and } \\
\text { PB }_{1,2}-b-\mathrm{PS}-b-\mathrm{PCHD}_{1,4}\end{array}$ & $\begin{array}{c}29-32 \\
\text { and } \\
39\end{array}$ & $110^{\circ} \mathrm{C}, 7$ days & LAM, $\mathrm{C}_{\mathrm{h}} \mathrm{C}$ & [63] \\
\hline 41 & PS- $b$-PB- $b$-PtBMA & $57-148$ & $\mathrm{n} / \mathrm{a}$ & $\mathrm{C}_{\mathrm{h}} \mathrm{C}, \mathrm{CSG}, \mathrm{LAM}, \mathrm{LC}$ & [64] \\
\hline 42 & PS- $b-\mathrm{PB}_{1,4}-b-\mathrm{PI}_{3,4}$ & 80-103 & $\begin{array}{l}130^{\circ} \mathrm{C}, 7 \text { days } \\
150^{\circ} \mathrm{C}, 5 \text { days }\end{array}$ & LAM, LAM/CSG & [65] \\
\hline 43 & PI- $b$-PS- $b$-P2VP & $122-124$ & $150^{\circ} \mathrm{C}, 5$ days & GS, LC & [66] \\
\hline 44 & PI- $b$-PS- $b$-P2VP & $223-264$ & $150^{\circ} \mathrm{C}, 5$ days & LS, HPC & [67] \\
\hline 45 & PS- $b-\mathrm{PB}_{1,4}-b-\mathrm{PI}_{3,4}$ & $35-43$ & $120^{\circ} \mathrm{C}, 5$ days & LAM & [68] \\
\hline 46 & PI- $b$-PS- $b$-P2VP & $136-146$ & $150^{\circ} \mathrm{C}, 5$ days & LAM & [69] \\
\hline 47 & PI- $b$-PS- $b-P 2 V P$ & 84 & $240{ }^{\circ} \mathrm{C}, 3 \mathrm{~h}$ & SPH/CYL & [70] \\
\hline 48 & PS- $b$-P2VP- $b$-PEO & $32-161$ & $130^{\circ} \mathrm{C}, 5$ days & LAM, HPC & [71] \\
\hline 49 & $\begin{array}{c}\text { PS- } b \text {-PI- } b \text {-PMMA } \\
\text { and } \\
\text { PI- } b \text {-PS- } b \text {-PMMA }\end{array}$ & $\begin{array}{c}171 \\
\text { and } \\
95-318\end{array}$ & $\begin{array}{l}80^{\circ} \mathrm{C}, 2 \text { days } \\
150^{\circ} \mathrm{C}, 6 \mathrm{~h}\end{array}$ & $\mathrm{HEL}_{0} \mathrm{C}, \mathrm{CSG}$ & [72] \\
\hline 50 & PS- $b$-PI- $b$-PMMA & $171-324$ & $\begin{array}{c}80^{\circ} \mathrm{C}, 2 \text { days } \\
150^{\circ} \mathrm{C}, 6 \mathrm{~h}\end{array}$ & 'planetlike', $\mathrm{HEL}_{\mathrm{o}} \mathrm{C}, \mathrm{S}_{\mathrm{o}} \mathrm{C}$ & [73] \\
\hline 51 & PS- $b$-PB- $b$-PMMA & 74-202 & $\mathrm{n} / \mathrm{a}$ & LAM, LS, LC & [74] \\
\hline
\end{tabular}

PS, polystyrene; PB, poly(butadiene); PA, poly[(4-vinylbenzyl)dimethylamine]; P4VP, poly(4-vinylpyridine); P2VP, poly(2-vinylpyridine); PI poly(isoprene); PDMS, poly(dimethylsiloxane); PMMA, poly(methyl methacrylate); PtBMA, poly(tert-butyl methacrylate); PEO, poly(ethylene oxide); PEB, poly(ethylene-co-butylene); PCHD, poly(cyclohexadiene); $\mathrm{PFS}^{\mathrm{a}}$, poly(dimethylsilaferrocenophane); PFS ${ }^{\mathrm{b}}$, poly(ferrocenylsilane); PCL, poly(E-caprolactone); $\mathrm{PH}$, poly(2-hydroxyethyl methacrylate); PF, poly[2 (perfluorobu-tyl) ethyl methacrylate]; P2T, poly(tert-butyl methacrylate); PVME, poly(vinyl methyl ether); n/a: not available. LAM, 3-phase 4-layer lamellae; CYL, cylindrical structure; OTDD, ordered tricontinuous double diamond; $\mathrm{SPH}$, spheres; $\mathrm{C}_{\mathrm{h}} \mathrm{C}$, hexagonally arranged core shell cylinders; LC, cylinders on lamellae; CR, rings on cylinders; LS, spheres on lamellae; HEL, helical morphologies; $\mathrm{KP}$, knitting pattern; $\mathrm{CYL}_{\mathrm{T}}$, tetragonally packed cylinders; $\mathrm{S}_{\mathrm{O}} \mathrm{C}$, spheres on cylinders; $\mathrm{C}_{\mathrm{a}} \mathrm{C}$, cylinder at cylinder; $\mathrm{uC}_{\mathrm{i}} \mathrm{C}$, perforated cylinder in cylinder; $\mathrm{S}_{\mathrm{o}} \mathrm{S}$, spheres on spheres; HPC, hexagonally packed cylinders; $\mathrm{CSG}$, core shell gyroid; Fddd $\left(\mathrm{O}^{70}\right)$, non-cubic orthorhombic network morphology; $\mathrm{Q}^{230}$, core shell double gyroid; $\mathrm{Q}^{214}$, alternating gyroid; LAM/CSG, coexistence of lamellae and gyroid; PLS, pillared lamellar structure; SPL, semi-perforated lamellae; PL, perforated lamellae; UL, undulated lamellae; dHEL, double helical structure; GS, sphere in gyroid structure; $\mathrm{HEL} / \mathrm{S}_{\mathrm{O}} \mathrm{C}$, coexistence of helical and spheres on cylinders; $\mathrm{HEL}_{\mathrm{o}} \mathrm{C}$, helices on cylinders; TPL, tetragonally perforated lamellae; SPH/CYL, coexistence of spheres and cylinders.

In this study, we report the synthesis and the molecular and morphological characterization of two samples of the PS- $b$ - $\mathrm{PB}_{1,4}-b$-PDMS type and one sample of the $\mathrm{PB}_{1,4}-b$-PS- $b$-PDMS sequence, exhibiting low values of total number average molecular weight, varying from $11.000 \mathrm{~g} / \mathrm{mol}$ up to $14.000 \mathrm{~g} / \mathrm{mol}$. The aim of this work is twofold: (a) to examine the self-assembly capability in such systems and (b) whether or not the microphase separation is affected when the elastomeric $\mathrm{PB}_{1,4}$ block is either the first block or the middle block, respectively, despite the very low number average molecular weight of this specific segment in all samples. It is the very first time in the literature, to the best of our knowledge, that such low number average molecular weight triblock terpolymers were synthesized and their structure/properties relationship was studied.

\section{Materials and Methods}

Anionic polymerization under high vacuum techniques, through monomer sequential addition, was employed to prepare these samples, in order to be considered well-defined materials with low dispersity indices and exhibiting molecular/compositional homogeneity. The purification of all 
reagents (monomers and solvents), as well as the dilution of the initiator, is described extensively elsewhere $[45,51,75,76]$. The synthesis procedure for all three samples, together with the appropriate molecular characterization (number average molecular weights and mass fractions of the three blocks) via size exclusion chromatography (SEC; Supplementary Materials Figures S1-S3), vapor pressure osmometry (VPO) and proton nuclear magnetic resonance spectroscopy $\left({ }^{1} \mathrm{H}-\mathrm{NMR}\right.$; Supplementary Materials Figures S4-S6 and Table S1), is given in the Supplementary Materials. The synthetic steps for the two different block sequences (PS- $b-\mathrm{PB}_{1,4}-b$-PDMS and $\mathrm{PB}_{1,4}-b$-PS- $b$-PDMS, respectively) are illustrated in Supplementary Materials Scheme S1a,b. The instruments used for the molecular characterization, size exclusion chromatography or SEC (Agilent Technologies/Polymer Labs, St. Clara, CA, USA) and proton nuclear magnetic resonance spectroscopy or ${ }^{1} \mathrm{H}-\mathrm{NMR}$ (Bruker $\mathrm{GmbH}$, Berlin, Germany) of the precursors, intermediated diblocks and final terpolymers are thoroughly described elsewhere [77]. The vapor pressure osmometry or VPO measurements were carried out at $45^{\circ} \mathrm{C}$, using dried toluene as solvent in a Gonotec 070 (Gonotec $\mathrm{GmbH}$, Berlin, Germany) vapor pressure osmometer.

Differential scanning calorimetry (DSC) experiments, for the thermal characterization, were accomplished by employing a TA Instruments Q20 DSC (TA Instruments Ltd., Leatherhead, UK). Two heating cycles and one cooling cycle were made. The first heating concluded to the erasure of the thermal behavior of the sample. The heating and cooling rate in all cycles was $10 \mathrm{~K} / \mathrm{min}$. The thermographs given (Supplementary Materials Figures S7-S9) correspond to the second heating cycle.

High-resolution transmission electron microscopy (HR-TEM) measurements, for the self-assembly characterization, were carried out in a JEOL 2100 TEM (JEOL Ltd., Tokyo, Japan), by using $200 \mathrm{KeV}$ as the acceleration voltage. The studied sample sections with thickness $\sim 30 \mathrm{~nm}$ were placed on 600 mesh $\mathrm{Cu}$ grids and were taken through cryo-ultramicrotoming (Leica EM UC7 from Leica Microsystems, Wetzlar, Germany) at $-140^{\circ} \mathrm{C}$ (temperature well below the lowest $\mathrm{T}_{\mathrm{g}}$ of the PDMS segments $\sim-120^{\circ} \mathrm{C}$ ). The studied sections were examined before and after staining with vapors of $\mathrm{OsO}_{4}\left(2 \% w / v \mathrm{OsO}_{4}\right.$ in water (Science Services, Munich, Germany)). It should be noted that the initial bulk films were prepared from solutions of the three samples in toluene $(5 \% w / v)$, where the solvent was left to slowly evaporate leading to bulk self-assembly of the terpolymers. More details are given in the main manuscript.

The synchrotron beam source from the beamline BL23A of the National Synchrotron Radiations Research Center (NSRRC) was used for the SAXS experiments at which a mirror and monochromatic to the energy of $10 \mathrm{keV}$ by a germanium (111) double-crystal monochromator was used to vertically focus the incident $X$-ray beam. The wavelength of the X-ray beam was $1.24 \AA$. The beam stop was a round tantalum disk $4 \mathrm{~mm}$ in diameter. A MAR CCD X-ray detector (Rayonix L.L.C., Evanston, IL, USA) was used to collect the two-dimensional (2D) SAXS patterns. The films studied for the SAXS experiments were parts from those prepared for the TEM studies prior ultra-cryomicrotoming.

\section{Results and Discussion}

Molecular and Thermal Characterization. The SEC, VPO and ${ }^{1} \mathrm{H}-\mathrm{NMR}$ results, as evident in Table 2, justify that the three different terpolymers can be considered well-defined materials.

Table 2. Molecular characteristics of all blocks of the three triblock terpolymers synthesized.

\begin{tabular}{|c|c|c|c|c|c|c|c|c|c|c|c|}
\hline Sample & $\mathrm{A}-b-\mathrm{B}-b-\mathrm{C}$ & $\begin{array}{l}\bar{M}_{n}^{A}{ }^{(a)} \\
(g / m o l)\end{array}$ & $\begin{array}{l}\bar{M}_{n}^{B(a)} \\
(g / m o l)\end{array}$ & $\begin{array}{l}\bar{M}_{\mathrm{n}}^{\mathrm{C}^{(a)}} \\
(\mathrm{g} / \mathrm{mol})\end{array}$ & $\begin{array}{l}\bar{M}_{n}^{\text {tot (a) }} \\
\text { (g/mol) }\end{array}$ & $\bigoplus^{\mathrm{SEC}(\mathbf{b})}$ & $f_{\mathrm{A}}{ }^{\text {(c) }}$ & $f_{\mathrm{B}}{ }^{(\mathrm{c})}$ & $f_{C}{ }^{(c)}$ & $\begin{array}{c}\mathrm{PB}_{1,4} \text { (c) } \\
(\%)\end{array}$ & $\begin{array}{c}\mathrm{PB}_{1,2}(\mathrm{c}) \\
(\%)\end{array}$ \\
\hline 1 & PS- $b$-PB $1,4^{-} b$-PDMS & 5.200 & 1.300 & 4.500 & 11.000 & 1.04 & 0.52 & 0.09 & 0.39 & 90 & 10 \\
\hline 3 & $\mathrm{~PB}_{1,4}$-b-PS- $b$-PDMS & 1.900 & 6.100 & 6.000 & 14.000 & 1.04 & 0.11 & 0.42 & 0.47 & 93 & 7 \\
\hline
\end{tabular}

(a) VPO in toluene at $45^{\circ} \mathrm{C}$. (b) Dispersity (Đ) calculated from SEC in THF at $30{ }^{\circ} \mathrm{C}$. ${ }^{\text {(c) }}$ Mass fractions for the three blocks and 1,4-/1,2-microstructure percentages for the PB segments calculated from ${ }^{1} \mathrm{H}-\mathrm{NMR}$ in $\mathrm{CDCl}_{3}$ at $25{ }^{\circ} \mathrm{C}$. 
Differential scanning calorimetry (DSC) experiments were carried out in order to verify the existence of the characteristic glass transition temperatures $\left(T_{g}\right)$ for the three chemically different segments. The DSC thermographs are evident in Supplementary Materials Figures S7-S9, and $\mathrm{T}_{\mathrm{g}}$ endothermal peaks were observed only for PS and PDMS segments, with values corresponding to low-molecular-weight PS $\left(65\right.$ to $\left.74{ }^{\circ} \mathrm{C}\right)$ and PDMS $\left(-121\right.$ to $\left.-119{ }^{\circ} \mathrm{C}\right)$ segments as reported in the literature [78-80]. The absence of the PB glass transition temperature is attributed to the very low number average molecular weight (varying in the three samples, from 1.300 to $1.900 \mathrm{~g} / \mathrm{mol}$ ) and also suggests that actually a two-phase system might be observed during microphase separation studies. Supplementary Materials Table S2 in indicates the entanglement $\left(\mathrm{M}_{\mathrm{e}}\right)$ and critical $\left(\mathrm{M}_{\mathrm{c}}\right)$ average molecular weights for each block, according to the literature, in order to justify the absence of any glass transition, especially for such low-molecular-weight PB segments, which are well below the preferred $\mathrm{M}_{\mathrm{e}}$ of $2.600 \mathrm{~g} / \mathrm{mol}$ (References [1-3] in the Supplementary Materials). Despite the fact that the PS according to Supplementary Materials Figures S7-S9, for all three samples, is well above room temperature (ranging from 65 to $74{ }^{\circ} \mathrm{C}$ ), the fact that its molecular weight is well above that of the PB does not lead to the probability of possible entrapment of the system in a non-preferred morphology.

Structure/Properties Relationship. The morphological characterization of the synthesized samples was achieved via transmission electron microscopy (TEM) and small angle X-ray scattering (SAXS). All samples were casted in toluene, which can be considered a good solvent for all blocks, showing preference to the PS, then to the PB and finally to the PDMS segments, according to the solubility parameters of the three blocks relative to that of toluene. As it is evident in the literature [40,41], the solubility parameter $\delta$ of the segments is $\delta_{\mathrm{PS}}=9.1 \mathrm{cal} / \mathrm{cm}^{3}, \delta_{\mathrm{PB}}=8.4 \mathrm{cal} / \mathrm{cm}^{3}$ and $\delta_{\mathrm{PDMS}}=7.3 \mathrm{cal} / \mathrm{cm}^{3}$, respectively, while, for toluene, the value is $\delta_{\text {tol }}=8.9 \mathrm{cal} / \mathrm{cm}^{3}$. Based on the aforementioned values and the literature [51], it is evident that PS microphase separates faster from the other two blocks and the final self-assembly in the corresponding three-phase structures occurs in a second step.

After the complete solvent evaporation, the bulk samples were ultra-cryomicrotomed in order to retrieve ultra-thin sections (with thickness below $30 \mathrm{~nm}$ due to the low molecular characteristics in order to achieve at least one unit cell in dimension, but no more than two, if complex morphologies were adopted) suitable for the subsequent morphological characterization.

Since one block is a polydiene, staining process with vapors of osmium tetroxide $\left(\mathrm{OsO}_{4}\right.$, Science Services, $2 \% w / v$ in water) was employed, in order to increase the electron density through crosslinking and thus enhance the image contrast of PB relative to the PS.

It should be mentioned that all samples exhibit extremely low average molecular weights, and, therefore, the microphase separation of these systems was conducted without performing thermal annealing for all cases. Additionally, for comparison reasons, the terpolymers were studied before and after staining with $\mathrm{OsO}_{4}$, in order to justify the existence of the third phase corresponding to PB in all cases.

According to Supplementary Materials Table S2, all segments in all three final terpolymers exhibit number average molecular weights well below the preferred entanglement $\left(\mathrm{M}_{\mathrm{e}}\right)$ average molecular weights $(2.600 \mathrm{~g} / \mathrm{mol}$ for PB, $16.500 \mathrm{~g} / \mathrm{mol}$ for PS and $10.000 \mathrm{~g} / \mathrm{mol}$ for the PDMS), leading to the conclusion that the chains are already stretched (without any entanglements), and therefore thermal annealing will not lead to any advancement of the already well-organized and adopted structures for all three terpolymers. Therefore, all the results from TEM and SAXS characterization correspond exclusively to unannealed samples. Furthermore, the values of the three different Flory-Huggins interaction parameters $\left(\chi_{\mathrm{PS} / \mathrm{PB}}, \chi_{\mathrm{PB} / \mathrm{PDMS}}\right.$ and $\left.\chi_{\mathrm{PS} / \mathrm{PDMS}}\right)$ are also given in Supplementary Materials Table S3, where the details of their theoretical calculations are provided based on equations known from the literature (References [4-7] in the Supplementary Materials).

In Figure 1, TEM images from both unstained and stained sections of sample 1 (PS- $b$-PB $1,4-b$-PDMS sequence with total $\bar{M}_{n}^{\text {tot }}$ of $11.000 \mathrm{~g} / \mathrm{mol}$ ) are shown. As expected, before staining, the microphase separation indicated a two-phase alternating lamellae morphology, due to the fact that PS and $\mathrm{PB}_{1,4}$ segments are miscible, since they possess similar electron density. As a result, $\mathrm{PS}$ and $\mathrm{PB}_{1,4}$ have a gray 
color, while the PDMS segments appear darker in the TEM micrograph, due to enhanced scattering cross-section of the silicon-containing block (Figure 1a). After staining with vapors of $\mathrm{OsO}_{4}$, the $\mathrm{PB}_{1,4}$ domains appear darker due to crosslinking and enhancement of the PB electron density, while the other blocks (i.e., PS and PDMS) appear lighter (white and gray, respectively), as evident in Figure $1 \mathrm{~b}$. From Figure $1 \mathrm{~b}$, for the $\mathrm{PB}_{1,4}$ segment, the layer thickness was calculated at approximately $\sim 1.9 \mathrm{~nm}$ $(\times 2)$, while, for the PDMS and the PS segments, the thickness was $\sim 3.8$ and $\sim 6.1 \mathrm{~nm}$, respectively, leading to a total approximate value of $14 \mathrm{~nm}$ for the d-spacing of the unit cell, as calculated by the TEM instrument capability (after correct calibration with specific standards at $200 \mathrm{kV}$, which is the accelerating voltage used for the TEM experiments).

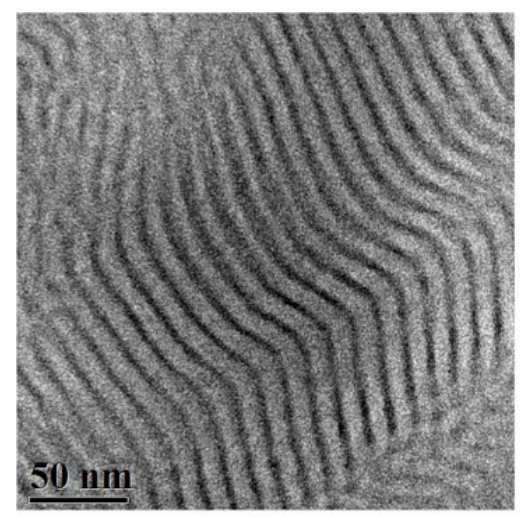

(a)

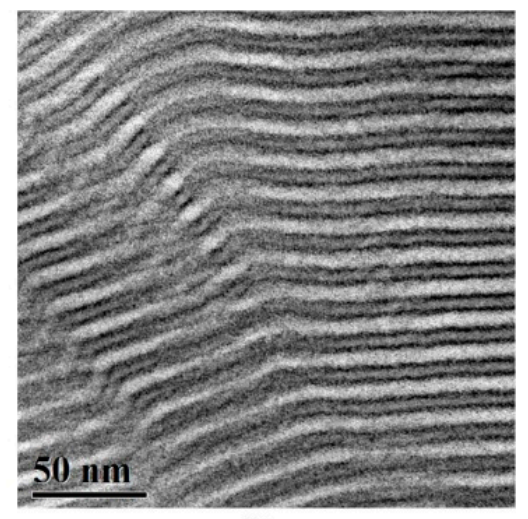

(b)

Figure 1. TEM images of the PS- $b-\mathrm{PB}_{1,4}-b$-PDMS terpolymer (sample 1 ). (a) Unstained sections where a two-phase alternating lamellae morphology is evident, with dark regions corresponding to PDMS and gray to the mixed $\mathrm{PS} / \mathrm{PB}_{1,4}$ segments, respectively. (b) Sections stained for $60 \mathrm{~min}$ with vapors of $\mathrm{OsO}_{4}$, leading to a very distinct three-phase four-layer alternating lamellae structure. Black corresponds to PB, white to PS and gray to PDMS domains.

According to the literature, in most cases, to obtain a three-phase four-layer lamellae morphology, a composition ratio of $1 / 1 / 1$ between the three blocks and equivalent interaction parameters $\chi$ between all components $\left(\chi_{\mathrm{AB}} \approx \chi_{\mathrm{BC}} \approx \chi_{\mathrm{AC}}\right)$ are required [81]. There are a few discrepancies from that rule reported in the literature for samples of the PI-b-PS-b-PMMA sequence, as reported by Epps and his research group [58].

For sample 1 , the block volume fraction ratio $\mathrm{PS} / \mathrm{PB} / \mathrm{PDMS}$ is approximately equal to $5 / 1 / 4$, and the Flory-Huggins interaction parameter values correspond to the inequality: $\chi_{\mathrm{PS} / \mathrm{PB}}<\chi_{\mathrm{PB} / \mathrm{PDMS}}<<$ $\chi_{\mathrm{PS} / \mathrm{PDMS}}$. Actually, microphase separation between the three chemically different blocks was not expected, as already mentioned in the DSC results.

Sample 2 (of the PS- $b$ - $\mathrm{PB}_{1,4}-b$-PDMS sequence), with a total $\overline{\mathrm{M}}_{\mathrm{n}}^{\mathrm{tot}}$ of $13.100 \mathrm{~g} / \mathrm{mol}$ and block volume fraction ratio $\mathrm{PS} / \mathrm{PB} / \mathrm{PDMS}$ approximately equal to $5 / 1 / 4$ (similar to that of sample 1), led to different morphological results when unstained and stained sections with vapors of $\mathrm{OsO}_{4}$ for $60 \mathrm{~min}$ (Figure 2a,b respectively) were studied. Again, after staining, a three-phase system occurs, but it is not a three-phase four-layer lamellae structure, as can be observed in Figure 2b.

The TEM image prior to staining indicates a structure very consistent to a cubic morphology relevant to the double gyroid morphology, since [111] and [100] high symmetry projections are evident (Figure 2a). A two-phase contrast is observed, where the darker phase corresponds to the PDMS (networks) and the gray domains (matrix) correspond to the mixture of $\mathrm{PS}$ and $\mathrm{PB}_{1,4}$. In this case, the mass fraction of PDMS is approximately 0.42 (leading to a volume fraction of 0.41 ), which is very close to that reported in the literature, by our group, where diblock copolymers of PS- $b$-PDMS sequences were studied and the DG morphology was observed for volume fractions of the PDMS segments equal to $\sim 0.41$ [82]. Moreover, the PDMS occupied the networks in the PS matrix in the copolymer, 
as is evident in the TEM image in Figure 2a. After staining with $\mathrm{OsO}_{4}$ for 60 min, three phases are observed (Figure 2b). High symmetry projections are evident corresponding to three-fold (hexagons) and four-fold (squares) symmetries, leading to the fact that a core-shell gyroid morphology is adopted where the networks are occupied by PS (white), covered peripherally by the lower in concentration PB (dark regions) in the matrix of PDMS (gray areas). Such images have already been reported in the literature for higher-molecular-weight samples and different sequences $[65,83]$.

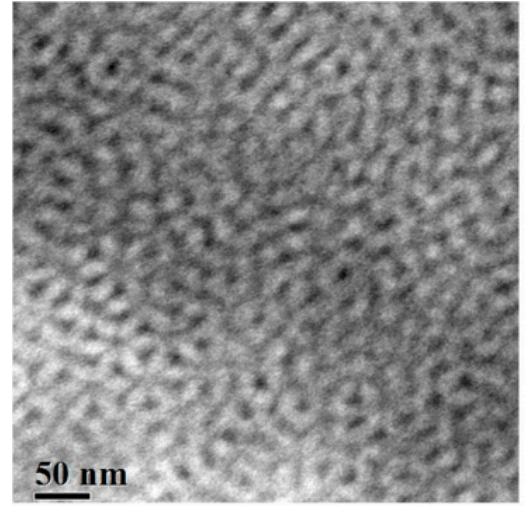

(a)

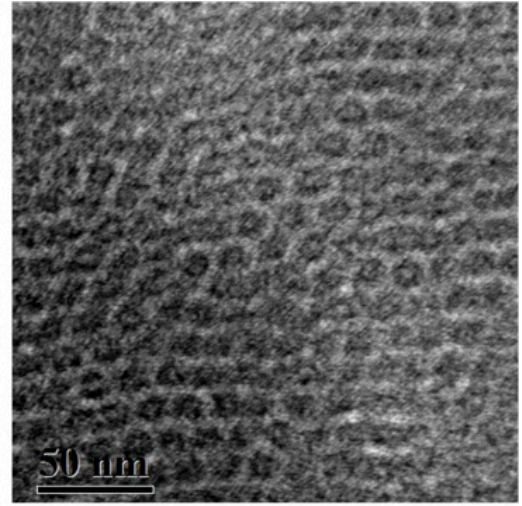

(b)

Figure 2. TEM images of the PS- $b$ - $\mathrm{PB}_{1,4}-b$-PDMS terpolymer (sample 2). (a) Unstained sections where a 2-phase morphology consistent with the DG structure is evident. Dark areas correspond to PDMS segments and gray to the $\mathrm{PS} / \mathrm{PB}_{1,4}$ mixed blocks. The existence of high symmetry projections (three-fold and four-fold) justifies the cubic morphology. (b) Sections stained for $60 \mathrm{~min}$ with vapors of $\mathrm{OsO}_{4}$, leading to a very distinct three-phase cubic microdomain structure consistent with the core-shell gyroid morphology. Black corresponds to PB segments, white to PS and gray to PDMS domains.

For sample 3 (of the $\mathrm{PB}_{1,4}-b$-PS- $b$-PDMS sequence), with a total $\overline{\mathrm{M}}_{\mathrm{n}}^{\text {tot }}$ of $14.000 \mathrm{~g} / \mathrm{mol}$ and block volume fraction ratio PS/PB/PDMS approximately equal to 4/1/5, TEM images from the unstained and stained sections with $\mathrm{OsO}_{4}$ are given in Figure 3.

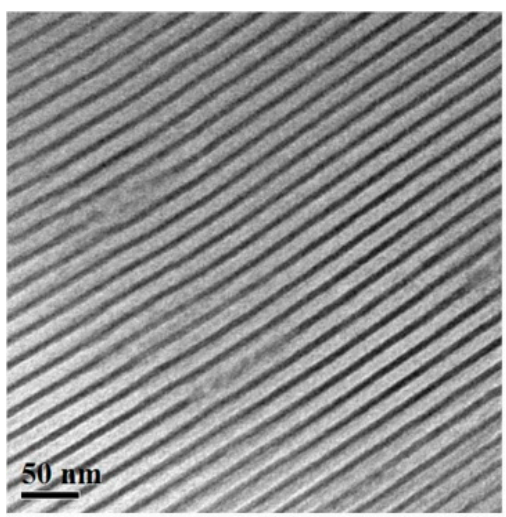

(a)

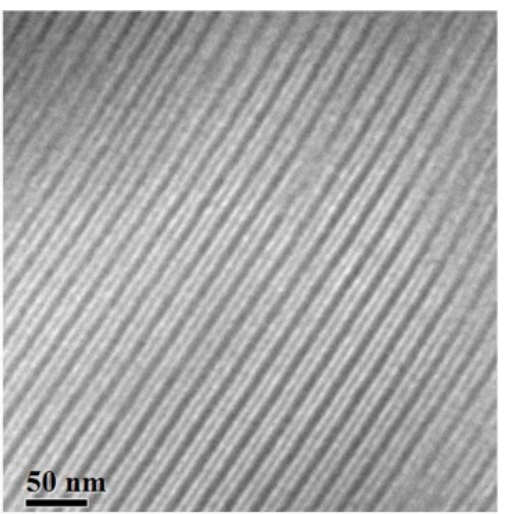

(b)

Figure 3. TEM images of the $\mathrm{PB}_{1,4}$ - $b$-PS- $b$-PDMS terpolymer (sample 3). (a) Unstained sections where a two-phase alternating lamellae morphology is evident, with dark regions corresponding to PDMS and gray to the mixed $\mathrm{PS} / \mathrm{PB}_{1,4}$ segments, respectively. (b) Sections stained for $30 \mathrm{~min}$ with vapors of $\mathrm{OsO}_{4}$, leading to a distinct three-phase four-layer alternating lamellae structure, as in sample 1, where the block sequence is different. Black corresponds to PB, white to PS and dark gray to PDMS domains.

Two-phase lamellae are observed for the unstained sections, leading again to white layers of the mixed phase of PS and PB and darker PDMS layers (Figure 3a). After staining with $\mathrm{OsO}_{4}$, a three-phase four-layer lamellae structure is evident (Figure 3b), with a color-contrast sequence different to that 
observed for sample 1 (Figure $1 \mathrm{~b}$ ), since, in this case, the middle block is the PS and not the $\mathrm{PB}_{1,4}$. This contrast difference is attributed to the decreased staining time with $\mathrm{OsO}_{4}$ vapors (30 min instead of $60 \mathrm{~min}$, as in the case of samples 1 and 2). This observation is very important, since it leads to the conclusion that the crosslinking of $\mathrm{PB}_{1,4}$ segments with $\mathrm{OsO}_{4}$ strongly depends on the staining duration time.

Despite the fact that the contrast between the PB and PDMS layers for sample 3 after staining is minimal (almost dark contrast for both blocks), the difference in layer thickness also clearly justifies the importance of thorough and analytical molecular characterization, since, for the $\mathrm{PB}_{1,4}$ segment, the layer thickness was calculated at approximately $\sim 2.4 \mathrm{~nm}$, while, for the PS and the PDMS segments, the thickness was $\sim 2.8 \mathrm{~nm}(\times 2)$ and $\sim 4.8 \mathrm{~nm}$, respectively, leading to a total approximate value of $\sim 13 \mathrm{~nm}$ for the d-spacing of the unit cell, as calculated by the TEM instrument capability. Again, in this sample, as in sample 1, a three-phase four-layer lamellae morphology is evident without the composition ratio between the three blocks being equal to $1 / 1 / 1$ and without having equivalent interaction parameters $\chi$ between all components $\left(\chi_{\mathrm{AB}} \approx \chi_{\mathrm{BC}} \approx \chi_{\mathrm{AC}}\right)$ [81].

In order to further investigate the obtained morphologies, small-angle $X$-ray scattering (SAXS) experiments were made and are illustrated in Figure 4. It is clear from the $\operatorname{lnI}(\mathrm{q})$ vs. q-plots that four and five peaks are visible, indicating that these samples, despite the considerably low number average molecular weight values, after casting even without any type of annealing, are well ordered in bulk, as evident also from the TEM images in Figures 1-3, and as mentioned already, due to their molecular characteristics below the $\mathrm{M}_{\mathrm{e}}$ for all segments. According to the International Tables for X-Ray Crystallography [84], the lamellae structure has a pm space group with permitted reflections [100], [200], [300], [400].

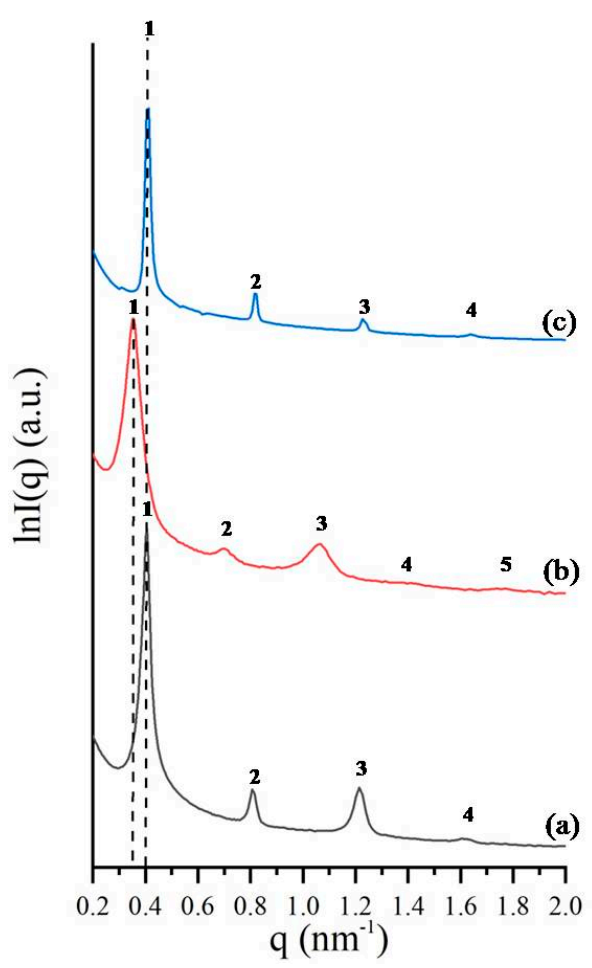

Figure 4. SAXS plots of $\ln \mathrm{I}(\mathrm{q})$ versus $\mathrm{q}$ for the three different triblock terpolymer samples: (a) PS- $b$-PB 1,4 - $b$-PDMS (sample 1), (b) PS- $b$-PB PB, $_{1,}-b$-PDMS (sample 2) and (c) $\mathrm{PB}_{1,4}$ - $b$-PS- $b$-PDMS (sample 3).

In line with the aforementioned requirement, the characteristic one-dimensional SAXS profile for sample 1 (Figure 4a) further justified the formation of a lamellar phase, since the relative q-values of the observed peaks correspond to a ratio of 1:2:3:4. Based on the value of the primary permitted peak 
and through the equation $\mathrm{q}=2 \pi / \mathrm{d}$, the domain spacing was calculated equal to $\mathrm{d}=15 \mathrm{~nm}$, which is in a good agreement with TEM results $(\sim 14 \mathrm{~nm})$.

For sample 2, the SAXS plot (Figure 4b) justified the formation of lamellae morphology and not a cubic structure as evidenced by the TEM images (Figure 2). The relative q-values of the observed peaks correspond again to a ratio of 1:2:3:4:5, corresponding to a very well-ordered lamellar structure. Such an observation has been made by our group [65] in a previous publication, where, for a triblock terpolymer of the PS- $b-\mathrm{PB}_{1,4}-b-\mathrm{PI}_{3,4}$ sequence (where $\mathrm{PI}_{3,4}$ is poly(isoprene) with high 3,4-microstructure, $\sim 60 \%$ ), the TEM images indicated the co-existence of three-phase four-layer lamellae, together with core-shell-DG, but the SAXS plot exhibited peaks corresponding exclusively to pm symmetry. In order to verify the SAXS results for sample 2, additional sections were taken and observed with TEM, in order to justify the existence of alternating lamellae together with the observed core-shell gyroid structure (Figure 2). Furthermore, it might be suggested that the system is close to a phase boundary; therefore, temperature change might lead to structural differentiations. We believe that the results obtained are very novel, and therefore additional samples will be synthesized in order to verify and justify the lowest possible dimensions that can be reached for such triblock terpolymer systems. Based on the value of the primary permitted peak and through the equation $q=2 \pi / d$, the domain spacing of the unit cell was calculated equal to $\mathrm{d}=16 \mathrm{~nm}$.

For sample 3, where the block sequence is different compared to samples 1 and 2, the lamellae morphology evident from TEM (Figure 3) is confirmed from the SAXS plot (Figure 4c). In this case, as in sample 1, the relative q-values of the observed peaks correspond to a ratio of 1:2:3:4. Based on the value of the primary permitted peak and through the equation $q=2 \pi / d$, the domain spacing was calculated equal to $d=16 \mathrm{~nm}$, which is in a good agreement with TEM results $(\sim 13 \mathrm{~nm})$.

\section{Conclusions}

To conclude, three novel and narrow dispersed triblock terpolymers with very low total number average molecular weights were synthesized via anionic polymerization, and their self-assembly was studied with TEM and SAXS techniques. The block sequence was either PS- $b$-PB $1,4-b$-PDMS (2 samples) or $\mathrm{PB}_{1,4}-b$-PS- $b$-PDMS (1 sample). Such terpolymers have never been reported in the literature, and this is the first time that terpolymers exhibiting very low molecular characteristics have self-assembled in bulk, exhibiting well-defined morphologies (three-phase four-layer lamellae and core-shell gyroid) without any thermal annealing processes. The TEM images exhibited two phases prior to the staining of the PB segments with vapors of $\mathrm{OsO}_{4}$ due to mixing of the PS and PB domains, whereas, after staining for $60 \mathrm{~min}$, the three phases were well illustrated. The TEM results are supported by the SAXS plots, since at least four prominent peaks are evident in all three samples. This study is very well supported by the already published article by Sinturel, Bates and Hillmyer [85], where the importance of low-molecular-weight diblock copolymers with high $\chi$ values in microelectronics industry and nanotechnology manufacturing methods with dimensions of sub-10 $\mathrm{nm}$ is elaborated. Since we have shown that sub-16 nm dimensions can be reached in our samples, we strongly believe that, under careful synthetic routes, even lower dimensions will be reached, thus enhancing the importance of these triblock terpolymers in nanopatterning applications.

Supplementary Materials: The following are available online. Scheme S1: Synthetic routes of (a) PS- $b$-PB $1,4^{-}$ $b$-PDMS and (b) $\mathrm{PB}_{1,4}-b$-PS- $b$-PDMS triblock terpolymers. Figure S1: SEC chromatographs of the PS precursor (red), the diblock intermediate product of PS- $b$ - $\mathrm{PB}_{1,4}$ type (blue) and the final triblock terpolymer (sample 1) of the PS- $b$-PB $1,4-b$-PDMS type (black). Figure S2: SEC chromatographs of the PS precursor (red), the diblock intermediate product of PS- $b$ - $\mathrm{PB}_{1,4}$ type (blue) and the final triblock terpolymer (sample 2 ) of the PS- $b$-PB $1,4-b$-PDMS type (black). Figure S3: SEC chromatographs of the PS precursor (red), the diblock intermediate product of PS- $b$-PB 1,4 type (blue), the unfractionated triblock terpolymer (green) and the final triblock terpolymer (sample 3 ) of the $\mathrm{PB}_{1,4}$ - $b$-PS- $b$-PDMS type (black). Figure S4: ${ }^{1} \mathrm{H}-\mathrm{NMR}$ spectrum of the PS- $b$-PB $1,4-b$-PDMS triblock terpolymer (sample 1). Figure S5: ${ }^{1} \mathrm{H}-\mathrm{NMR}$ spectrum of the PS- $b$-PB $1,4-b$-PDMS triblock terpolymer (sample 2). Figure S6: ${ }^{1} \mathrm{H}-\mathrm{NMR}$ spectrum of the $\mathrm{PB}_{1,4}-b$-PS- $b$-PDMS triblock terpolymer (sample 3 ). Table S1: The type and number of protons per monomeric unit of each block, as well as the chemical shifts, are presented in order to comprehend the ${ }^{1} \mathrm{H}-\mathrm{NMR}$ spectra of the terpolymers. Table S2: Entanglement $\left(\mathrm{M}_{\mathrm{e}}\right)$ and critical $\left(\mathrm{M}_{\mathrm{c}}\right)$ average molecular weights 
for the three different blocks in the synthesized final triblock terpolymers. Figure S7: DSC thermograph of the PS- $b-\mathrm{PB}_{1,4}-b$-PDMS triblock terpolymer (sample 1 ), where only the two $\mathrm{T}_{\mathrm{g}} \mathrm{S}$ of PS and PDMS are evident. Figure S8: DSC thermograph of the PS- $b$ - $\mathrm{PB}_{1,4}-b$-PDMS triblock terpolymer (sample 2), where only the two $\mathrm{T}_{\mathrm{g}} \mathrm{P}$ of PS and PDMS are evident, together with the $\mathrm{T}_{\mathrm{c}}$ and $\mathrm{T}_{\mathrm{m}}$ of PDMS. Figure S9: DSC thermograph of the PB $1,4-b-\mathrm{PS}-b$-PDMS triblock terpolymer (sample 3), where only the two $T_{g}$ s of PS and PDMS are evident together with the $T_{c}$ and $T_{m}$ of PDMS. Table S3: Flory-Huggins $\chi$ interaction parameter for PS/PDMS and PS/PB 1,4 .

Author Contributions: Conceptualization, A.A.; methodology, C.M., I.M., G.-M.M., K.A. and D.M.; validation, A.A., D.A.I. and R.-M.H.; formal analysis, A.A., C.M., I.M., G.-M.M., K.A. and D.M.; data curation, A.A., C.M., I.M., G.-M.M., K.A., C.-Y.C., D.M. and E.A.B.; writing—original draft preparation, A.A., C.M., I.M., G.-M.M., K.A. and D.M.; writing-review and editing, A.A., R.-M.H. and D.A.I.; supervision, A.A. All authors have read and agreed to the published version of the manuscript.

Funding: A.A., D.M., D.A.I. and E.A.B. acknowledge financial support from the Ministry of Science and Higher Education of the Russian Federation within State Contract 075-15-2019-1889. D.A.I. and E.A.B. performed their work in accordance with State Task No. AA 19-119101590029-0. The research work was partially supported by the Hellenic Foundation for Research and Innovation (HFRI), under the HFRI PhD Fellowship grant (fellowship no. 1651) for G.-M.M. The research work was partially supported by the Hellenic Foundation for Research and Innovation (HFRI), under the HFRI PhD Fellowship grant (fellowship no. 1650) for I.M. The research work was also supported by the Hellenic Foundation for Research and Innovation (H.F.R.I.), under the "First Call for H.F.R.I. Research Projects to support Faculty members and Researchers and the procurement of high-cost research equipment grant" (Project Number: 3970, acronym: NANOPOLYBRUSH).

Acknowledgments: C.M., I.M., G.-M.M., K.A., D.M. and A.A. would like to acknowledge the Network of Research Supporting Laboratories at the University of Ioannina for letting them use the Electron Microscopy Facility and the Nuclear Magnetic Resonance Spectroscopy Center. The National Synchrotron Radiation Research Center (NSRRC) is also acknowledged for its assistance in the Synchrotron SAXS experiments.

Conflicts of Interest: The authors declare no conflict of interest.

\section{References}

1. Bates, F.S.; Fredrickson, G.H. Block copolymer thermodynamics: Theory and experiment. Ann. Rev. Phys. Chem. 1990, 41, 525-557. [CrossRef]

2. Bates, F.S. Polymer-polymer phase behavior. Science 1991, 251, 898-904. [CrossRef] [PubMed]

3. Park, C.; Yoon, J.; Thomas, E.L. Enabling nanotechnology with self-assembled block copolymer patterns. Polymer 2003, 44, 6725-6760. [CrossRef]

4. Hu, H.; Gopinadhant, M.; Osuji, C.O. Directed self-assembly of block copolymer: A tutorial review of strategies for enabling nanotechnology with soft matter. Soft Matter 2014, 10, 3867-3889. [CrossRef] [PubMed]

5. Borah, D.; Cummins, C.; Rasappa, S.; Senthmaraikannan, R.; Salaun, M.; Zelsmann, M.; Liontos, G.; Ntetsikas, K.; Avgeropoulos, A.; Morris, M.A. Nanopatterning via self-assembly of a lamellar-forming Polystyrene-block-Poly(dimethylsiloxane) diblock copolymer on topographical substrates fabricated by nanoimprint lithography. Nanomaterials 2018, 8, 32. [CrossRef] [PubMed]

6. Borah, D.; Rasappa, S.; Salaun, M.; Zelsmann, M.; Lorret, O.; Liontos, G.; Ntetsikas, K.; Avgeropoulos, A.; Morris, M.A. Soft graphoepitaxy for large area directed self-assembly of Polystyrene-blockPoly(dimethylsiloxane) block copolymer on nanopatterned POSS Substrates facricated by nanoimprint lithography. Adv. Funct. Mater. 2015, 25, 3425-3432. [CrossRef]

7. Choi, P.; Fu, P.-F.; Guo, L.J. Siloxane Copolymers for Nanoimprint Lithography. Adv. Funct. Mater. 2007, 17, 65-70. [CrossRef]

8. Jung, Y.S.; Ross, C.A. Orientation-controlled self-assembled nanolithography using a polystyrenepolydimethylsiloxane block copolymer. Nano Lett. 2007, 7, 2046-2050. [CrossRef]

9. Tu, K.-H.; Bai, W.; Liontos, G.; Ntetsikas, K.; Avgeropoulos, A.; Ross, C.A. Universal pattern transfer methods for metal nanostructures by block copolymer lithography. Nanotechnology 2015, 26, 375301. [CrossRef]

10. Chao, C.-C.; Wang, T.-C.; Ho, R.-M.; Georgopanos, P.; Avgeropoulos, A.; Thomas, E.L. Robust block copolymer mask for nanopatterning polymer films. ACS Nano 2010, 4, 2088-2094. [CrossRef]

11. Chao, C.-C.; Ho, R.-M.; Georgopanos, P.; Avgeropoulos, A.; Thomas, E.L. Silicon oxy carbide nanorings from polystyrene- $b$-polydimethylsiloxanediblock copolymer thin films. Soft Matter 2010, 6, 3582-3587. [CrossRef]

12. Tavakkoli, A. Templating three-dimensional self-assembled structures in bilayer block copolymer films. Science 2012, 336, 1294-1298. [CrossRef] [PubMed] 
13. Lo, T.-Y.; Dehghan, A.; Georgopanos, P.; Avgeropoulos, A.; Shi, A.-C.; Ho, R.-M. Orienting block copolymer thin films via entropy. Macromolecules 2016, 49, 624-633. [CrossRef]

14. Lee, K.; Kreider, M.; Bai, W.; Cheng, L.-C.; Dinachali, S.S.; Tu, K.-H.; Huang, T.; Ntetsikas, K.; Liontos, G.; Avgeropoulos, A.; et al. UV-solvent annealing od PDMS-majority and PS-minority PS- $b$-PDMS block copolymer films. Nanotechnology 2016, 27, 465301. [CrossRef] [PubMed]

15. Jackson, E.A.; Hillmyer, M.A. Nanoporous membranes derived from block copolymers: From drug delivery to water filtration. ACS Nano 2010, 4, 3548-3553. [CrossRef]

16. Zhang, Y.; Mulvenna, R.A.; Qu, S.; Boudouris, B.W.; Phillip, W.A. Block polymer membranes functionalized with nanoconfinement polyelectrolyte brushes achieve sub-nanometer selectivity. ACS Macro Lett. 2017, 6, 726-732. [CrossRef]

17. Ahn, H.; Park, S.; Kim, S.-W.; Yoo, P.J.; Ryu, D.Y.; Russell, T.P. Nanoporous block copolymer membranes for ultrafiltration: A simple approach to size tunability. ACS Nano 2014, 8, 11745-11752. [CrossRef]

18. Chang, A.B.; Bates, F.S. The ABCs of block polymers. Macromolecules 2020, 53, 2765-2768. [CrossRef]

19. Gido, S.P.; Schwark, D.W.; Thomas, E.L.; Goncalves, M.D. Observation of a non-constant mean curvature interface in an ABC Triblock copolymer. Macromolecules 1993, 26, 2636-2640. [CrossRef]

20. Mogi, Y.; Kotsuji, H.; Kaneko, Y.; Mori, K.; Matsushita, Y.; Noda, I. Preparation and morphology of Triblock copolymers of the ABC Type. Macromolecules 1992, 25, 5408-5411. [CrossRef]

21. Mogi, Y.; Mori, K.; Matsushita, Y.; Noda, I. Tricontinuous morphology of Triblock copolymers of the ABC Type. Macromolecules 1992, 25, 5412-5415. [CrossRef]

22. Mogi, Y.; Nomura, M.; Kotsuji, H.; Ohnishi, K.; Matsushita, Y.; Noda, I. Superlattice structures in morphologies of the ABC Triblock copolymers. Macromolecules 1994, 27, 6755-6760. [CrossRef]

23. Arai, K.; Kotaka, T.; Kitano, Y.; Yoshimura, K. Poly(styrene-b-butadiene- $b$-4-vinylpyridine) three block polymers. Synthesis, characterization, morphology, and mechanical properties. Macromolecules 1980, 13, 1670-1678. [CrossRef]

24. Arai, K.; Kotaka, T.; Kitano, Y.; Yoshimura, K. Synthesis and morphological behavior of a new ABC three-block polymer. Macromolecules 1980, 13, 455-457. [CrossRef]

25. Matsushita, Y.; Yamada, K.; Hattori, T.; Fujimoto, T.; Sawada, Y.; Nasagawa, M.; Matsui, C. Morphologies of ABC-Type Triblock copolymers with different compositions. Macromolecules 1983, 16, 10-13. [CrossRef]

26. Kudose, I.; Kotaka, T. Morphological and Viscoelastic Properties of Poly(styrene- $b$-butadiene- $b$-4vinylpyridine) three block polymers of the ABC Type. Macromolecules 1984, 17, 2325-2332. [CrossRef]

27. Mogi, Y.; Mori, K.; Kotsuji, H.; Matsushita, Y.; Noda, I. Molecular weight dependence of the lamellar domain spacing of ABC Triblock copolymers and their chain conformation in lamellar domains. Macromolecules 1993, 26, 5169-5173. [CrossRef]

28. Watanabe, H.; Shimura, T.; Kotaka, T.; Tirrell, M. Synthesis, characterization, and surface structures of styrene-2-vinylpyridine-butadiene three-block polymers. Macromolecules 1993, 26, 6338-6345. [CrossRef]

29. Matsushita, Y.; Tamura, M.; Noda, I. Tricontinuous double-diamond structure formed by a Styrene-Isoprene-2Vinylpyridine Triblock copolymer. Macromolecules 1994, 27, 3680-3682. [CrossRef]

30. Auschra, C.; Stadler, R. New ordered morphologies in ABC triblock copolymers. Macromolecules 1993, 26, 2171-2174. [CrossRef]

31. Stadler, R.; Auschra, C.; Beckmann, J.; Krappe, U.; Voight-Martin, I.; Leibler, L. Morphology and Thermodynamics of symmetric Poly(A-block-B-block-C) Triblock copolymers. Macromolecules 1995, 28, 3080-3097. [CrossRef]

32. Krappe, U.; Stadler, R.; Voight-Martin, I. Chiral Assembly in Amorphous ABC Triblock Copolymers. Formation of a Helical Morphology in Polystyrene-block-polybutadiene-block-poly(methyl methacrylate) Block Copolymers. Macromolecules 1995, 28, 4558-4561. [CrossRef]

33. Balsamo, V.; von Gyldenfeldt, F.; Stadler, R. Thermal Behavior and spherulitic superstructures of SBC triblock copolymers based on polystyrene (S), polybutadiene (B) and a crystallizable poly ( $\varepsilon$-caprolactone) (C) block. Macromol. Chem. Phys. 1996, 197, 3317-3341. [CrossRef]

34. Breiner, U.; Krappe, U.; Stadler, R. Evolution of the "knitting pattern" morphology in ABC triblock copolymers. Macromol. Rapid Commun. 1996, 17, 567-575. [CrossRef]

35. Jung, K.; Abetz, V.; Stadler, R. Thermodynamically Controlled Morphological Disorder in a MicrophaseSeparated Cylindrical Block Copolymer. Macromolecules 1996, 29, 1076-1078. [CrossRef] 
36. Breiner, U.; Krappe, U.; Abetz, V.; Stadler, R. Cylindrical morphologies in asymmetric ABC triblock copolymers. Macromol. Chem. Phys. 1997, 198, 1051-1083. [CrossRef]

37. Giebeler, E.; Stadler, R. ABC triblock polyampholytes containing a neutral hydrophobic block, a polyacid and a polybase. Macromol. Chem. Phys. 1997, 198, 3815-3825. [CrossRef]

38. Breiner, U.; Krappe, U.; Jakob, T.; Abetz, V.; Stadler, R. Spheres on spheres-A novel spherical multiphase morphology in polystyrene-block-polybutadiene-block-poly(methyl methacrylate) triblock copolymers. Polym. Bull. 1998, 40, 219-226. [CrossRef]

39. Neumann, C.; Abetz, V.; Stadler, R. Phase behavior of ABC-triblock copolymers with two inherently miscible blocks. Colloid Polym. Sci. 1998, 276, 19-27. [CrossRef]

40. Brinkmann, S.; Stadler, R.; Thomas, E.L. New structural Motif in Hexagonally Ordered Cylindrical Ternary (ABC) Block Copolymer Microdomains. Macromolecules 1998, 31, 6566-6572. [CrossRef]

41. Breiner, U.; Krappe, U.; Thomas, E.L.; Stadler, R. Structural characterization of the "Knitting Pattern" in Polystyrene-block-poly(ethylene-co-butylene)-block-poly(methyl methacrylate) triblock copolymers. Macromolecules 1998, 31, 135-141. [CrossRef]

42. Tanaka, Y.; Hasegawa, H.; Hashimoto, T.; Ribbe, A.; Sugiyama, K.; Hirao, A.; Nakayama, S. A Study of Three-phase structures in ABC Triblock copolymers. Polym. J. 1999, 31, 989-994. [CrossRef]

43. Shefelbine, T.A.; Vigild, M.E.; Matsen, M.W.; Hadjuk, D.A.; Hillmyer, M.A.; Cussler, E.L.; Bates, F.S. Core-Shell gyroid morphology in a Poly(isoprene-block-styrene-block-dimethylsiloxane) Triblock copolymer. J. Am. Chem. Soc. 1999, 121, 8457-8465. [CrossRef]

44. Huckstadt, H.; Gopfert, A.; Abetz, V. Influence of the block sequence on the morphological behavior of ABC triblock copolymers. Polymer 2000, 41, 9089-9094. [CrossRef]

45. Bellas, V.; Iatrou, H.; Hadjichristidis, N. Controlled Anionic Polymerization of Hexamethylcyclotrisiloxane. Model Linear and Miktoarm Star Co- and Terpolymers of Dimethylsiloxane with Styrene and Isoprene. Macromolecules 2000, 33, 6993-6997. [CrossRef]

46. Hückstädt, H.; Goldacker, T.; Göpfert, A.; Abetz, V. Core-Shell Double Gyroid Morphologies in ABC Triblock Copolymers with Different Chain Topologies. Macromolecules 2000, 33, 3757-3761. [CrossRef]

47. Bailey, T.S.; Pham, H.D.; Bates, F.S. Morphological behavior bridging the symmetric AB and ABC States in the Poly(styrene- $b$-isoprene- $b$-ethylene oxide) TriblockCopolymer System. Macromolecules 2001, 34, 6994-7008. [CrossRef]

48. Ott, H.; Abetz, V.; Altstädt, V. Morphological Studies of Poly(styrene)-block-poly(ethylene-co-butylene)block-poly(methyl methacrylate) in a composition region of the "Knitting Pattern" morphology. Macromolecules 2001, 34, 2121-2128. [CrossRef]

49. Bailey, T.; Hardy, C.; Epps, T.H.; Bates, F.S. A Noncubic Triply Periodic Network Morphology in Poly(isoprene- $b$-styrene- $b$-ethylene oxide) Triblock Copolymers. Macromolecules 2002, 35, 7007-7017. [CrossRef]

50. Yamauchi, K.; Hasegawa, H.; Hashimoto, T.; Köhler, N.; Knoll, K. Synthesis and morphological studies of polyisoprene-block-polystyrene-block-poly(vinyl methyl ether) triblock terpolymer. Polymer 2002, 43, 3563-3570. [CrossRef]

51. Avgeropoulos, A.; Paraskeva, S.; Hadjichristidis, N.; Thomas, E.L. Synthesis and Microphase Separation of Linear Triblock Terpolymers of Polystyrene, High 1,4-Polybutadiene, and High 3,4-Polyisoprene. Macromolecules 2002, 35, 4030-4035. [CrossRef]

52. Ludwigs, S.; Böker, A.; Abetz, V.; Müller, A.H.E.; Krausch, G. Phase behavior of linear polystyrene-blockpoly(2-vinylpyridine)-block-poly(tert-butyl methacrylate) triblock terpolymers. Polymer 2003, 44, 6815-6823. [CrossRef]

53. Epps, T.H., III; Cochran, E.W.; Bailey, T.S.; Waletzko, R.S.; Hardy, C.M.; Bates, F.S. Ordered network phases in linear Poly(isoprene-b-styrene- $b$-ethylene oxide) Triblock Copolymers. Macromolecules 2004, 37, 8325-8341. [CrossRef]

54. Epps, T.H., III; Bates, F.S. Effect of molecular weight on network formation in linear ABC Triblock copolymers. Macromolecules 2006, 39, 2676-2682. [CrossRef]

55. Kloninger, C.; Rehahn, M. Styrene-ferrocenyldimethylsilane-methyl methacrylate Triblock copolymers: Synthesis and phase morphology. Macromol. Chem. Phys. 2007, 208, 833-840. [CrossRef]

56. Jinnai, H.; Kaneko, T.; Matsunaga, K.; Abetz, C.; Abetz, V. A double helical structure formed from an amorphous, achiral ABC triblock terpolymer. Soft Matter 2009, 5, 2042-2046. [CrossRef] 
57. Chuang, V.P.; Gwyther, J.; Mickiewicz, R.A.; Manners, I.; Ross, C.A. Templated Self-Assembly of Square Symmetry Arrays from an ABC Triblock Terpolymer. Nano Lett. 2009, 9, 4364-4369. [CrossRef]

58. Tureau, M.S.; Epps, T.H., III. Nanoscale networks in Poly[isoprene-block-styrene-block-(methyl methacrylate)] Triblock copolymers. Macromol. Rapid Commun. 2009, 30, 1751-1755. [CrossRef]

59. Schacher, F.; Yuan, J.; Schoberth, H.G.; Müller, A.H.E. Synthesis, characterization, and bulk crosslinking of polybutadiene-block-poly(2-vinyl pyridine)-block-poly(tert-butyl methacrylate) block terpolymers. Polymer 2010, 51, 2021-2032. [CrossRef]

60. Matsushita, Y.; Suzuki, J.; Izumi, Y.; Matsuoka, K.; Takahashi, S.; Aoyama, Y.; Mihira, T.; Takano, A. Formation of undulated lamellar structure from ABC block terpolymer blends with different chain lengths. J. Chem. Phys. 2010, 133, 194901. [CrossRef]

61. Phillip, W.A.; Dorin, R.M.; Werner, J.; Hoek, E.M.V.; Wiesner, U.; Elimelech, M. Tuning structure and properties of graded triblock terpolymer-based mesoporous and hybrid films. Nano Lett. 2011, 11, 2892-2900. [CrossRef] [PubMed]

62. Schacher, F.H.; Sugimori, H.; Hong, S.; Jinnai, H.; Müller, A.H.E. Tetragonally Perforated Lamellae of Polybutadiene-block-poly(2-vinylpyridine)-block-poly(tert-butyl methacrylate) (BVT) Triblock Terpolymers in the Bulk: Preparation, Cross-Linking, and Dissolution. Macromolecules 2012, 45, 7956-7963. [CrossRef]

63. Kumar, R.; Sides, S.W.; Goswami, M.; Sumpter, B.G.; Hong, K.; Wu, X.; Russell, T.P.; Gido, S.P.; Misichronis, K.; Rangou, S.; et al. Morphologies of ABC Triblock terpolymer melts containing Poly(Cyclohexadiene): Effects of conformational asymmetry. Lagmuir 2013, 29, 1995-2006. [CrossRef] [PubMed]

64. Löbling, T.I.; Hiekkataipale, P.; Hanisch, A.; Bennet, F.; Schmalz, H.; Ikkala, O.; Gröschel, A.H.; Müller, A.H.E. Bulk morphologies of polystyrene-block-polybutadiene-block-poly(tert-butyl methacrylate) triblock terpolymers. Polymer 2015, 72, 479-489. [CrossRef]

65. Zapsas, G.; Moschovas, D.; Ntetsikas, K.; Rangou, S.; Lee, J.-H.; Thomas, E.L.; Zafeiropoulos, N.E.; Avgeropoulos, A. Immiscible polydiene blocks in linear copolymer and terpolymer sequences. J. Polym. Sci. Part B Polym. Phys. 2015, 53, 1238-1246. [CrossRef]

66. Asai, Y.; Takano, A.; Matsushita, Y. Creation of cylindrical morphologies with extremely large oblong unit lattices from ABC block terpolymer blends. Macromolecules 2015, 48, 1538-1542. [CrossRef]

67. Asai, Y.; Takano, A.; Matsushita, Y. Asymmetric double tetragonal domain packing from ABC Triblock Terpolymer blends with chain length difference. Macromolecules 2016, 49, 6940-6946. [CrossRef]

68. Ntaras, C.; Polymeropoulos, G.; Zapsas, G.; Ntetsikas, K.; Liontos, G.; Karanastasis, A.; Moschovas, D.; Rangou, S.; Stewart-Sloan, C.; Hadjichristidis, N.; et al. Synthesis, characterization and self-assembly of well-defined linear heptablockquaterpolymers. J. Polym. Sci. Part B Polym. Phys. 2016, 54, 1443-1449. [CrossRef]

69. Asai, Y.; Suzuki, J.; Aoyama, Y.; Nishioka, H.; Takano, A.; Matsushita, Y. Tricontinuous double diamond network structure from binary blends of ABC Triblock Terpolymers. Macromolecules 2017, 50, 5402-5411. [CrossRef]

70. Ahn, S.; Kwak, J.; Choi, C.; Seo, Y.; Kim, J.K. Gyroid structures at highly asymmetric volume fractions by blending of ABC Triblock terpolymer and AB diblock copolymer. Macromolecules 2017, 50, 9008-9014. [CrossRef]

71. Musteata, V.; Sutisna, B.; Polymeropoulos, G.; Avgeropoulos, A.; Meneau, F.; Peinermann, K.-V.; Hadjichristidis, N.; Nunes, S.P. Self-assembly of polystyrene-b-poly(2-vinylpyridine)-b-poly(ethylene oxide) triblock terpolymers. Eur. Polym. J. 2018, 100, 121-131. [CrossRef]

72. Haenelt, T.G.; Abetz, C.; Abetz, V. Morphological control over three- and four-phase superstructures in blends of asymmetric ABC and BAC Triblock Terpolymers. Macromol. Chem. Phys. 2018, 219, 1800383. [CrossRef]

73. Haenelt, T.G.; Meyer, A.; Abetz, C.; Abetz, V. Planet-like nanostructures formed by an ABC Triblock Terpolymer. Macromol. Chem. Phys. 2019, 220, 1900297. [CrossRef]

74. Steinhaus, A.; Chakroun, R.; Müllner, M.; Nghiem, T.-L.; Hilderbrandt, M.; Gröschel, A.H. Confinement Assembly of ABC TriblockTerpolymers for the High -Yield Synthesis of Janus Nanorings. ACS Nano 2019, 13, 6269-6278. [CrossRef]

75. Hadjichristidis, N.; Iatrou, H.; Pispas, S.; Pitsikalis, M. Anionic polymerization: High vacuum techniques. J. Polym. Sci. Part A Polym. Chem. 2000, 38, 3211-3234. [CrossRef] 
76. Uhrig, D.; Mays, J.W. Experimental Techniques in High-Vacuum Anionic Polymerization. J. Polym. Sci. Part A Polym. Chem. 2005, 43, 6179-6222. [CrossRef]

77. Moschovas, D.; Manesi, G.-M.; Karydis-Messinis, A.; Zapsas, G.; Ntetsikas, K.; Zafeiropoulos, N.E.; Piryazev, A.; Thomas, E.L.; Hadjichristidis, N.; Ivanov, D.A.; et al. Alternating gyroid network structure in an abc miktoarm terpolymer comprised of polystyrene and two polydienes. Nanomaterials 2020, 10, 1497. [CrossRef]

78. Fox, G.T.; Flory, P.J. The glass temperature and related properties of polystyrene. Influence of molecular weight. J. Polym. Sci. 1954, 75, 315-319. [CrossRef]

79. Cowie, J.M.G.; McEven, I.N. Molecular motions in poly(dimethyl siloxane) oligomers and polymers. Polymer 1973, 14, 423-426. [CrossRef]

80. Hintermeyer, J.; Herrmann, A.; Kahlau, R.; Goiceanu, C.; Rössler, E.A. Molecular weight dependence of glassy dynamics in linear polymers revisited. Macromolecules 2008, 41, 9335-9344. [CrossRef]

81. Bates, F.S.; Fredrickson, G.H. Block copolymers-Designer of soft materials. Physics Today 1999, 52, 32-38. [CrossRef]

82. Politakos, N.; Ntoukas, E.; Avgeropoulos, A.; Krikorian, V.; Pate, B.D.; Thomas, E.L.; Hill, R.M. Strongly segregated cubic microdomain morphology consistent with the double gyroid phase in high molecular weight diblock copolymers of polystyrene and poly(dimethylsiloxane). J. Polym. Sci. Part B Polym. Phys. 2009, 47, 2419-2427. [CrossRef]

83. Goldacker, T.; Abetz, V. Core-Shell cylinders and core-shell gyroid morphologies via blending of lamellar ABC Triblock and BC diblock copolymers. Macromolecules 1999, 32, 5165-5167. [CrossRef]

84. Hahn, T. International tables for X-ray crystallography. In Volume A: Space Group Symmetry, 5th ed.; Springer: New York, NY, USA, 2006; p. 94.

85. Sinturel, C.; Bates, F.S.; Hillmyer, M.A. High $\chi$-Low $N$ block polymers: How far can we go? ACS Macro Lett. 2015, 4, 1044-1050. [CrossRef]

Publisher's Note: MDPI stays neutral with regard to jurisdictional claims in published maps and institutional affiliations.

(C) 2020 by the authors. Licensee MDPI, Basel, Switzerland. This article is an open access article distributed under the terms and conditions of the Creative Commons Attribution (CC BY) license (http://creativecommons.org/licenses/by/4.0/). 